\title{
Poor self-rated oral health associated with poorer general health among Indigenous Australians
}

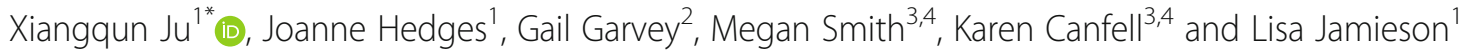

\begin{abstract}
Background: Oral diseases negatively impact general health, affecting physical, psychological, social and emotional wellbeing, and ability to give back to community. The relationship between poor oral health, and general health and wellbeing among Indigenous Australians has not been documented. Working in partnership with seven Indigenous communities in South Australia, this study aimed to: 1) quantify self-rated oral health and health-related quality of life and; 2 ) investigate associations between poor self-rated oral health and general health among Indigenous Australian adults.

Methods: Data was collected from a large convenience sample of Indigenous Australians aged 18+ years from Feb 2018 to Jan 2019. General health-related quality of life, as the main outcome variable, was measured by calculating disutility scores with the five individual EQ-5D dimensions (EuroQol instrument: EQ-5D-5L), then classified as 'no problem' and 'at least one problem'. Self-reported oral health, as the main explanatory, was dichotomised into 'fair or poor' and 'excellent, very good or good'. Multivariable log-Poisson regression models were used to estimate associations between poor self-rated oral health and general health by calculating mean rate ratios (MRR) for disutility scores and prevalence ratios (PR) for individual dimensions, after adjusting for social-demographic characteristics and health-related behaviours.
\end{abstract}

Results: Data were available for 1011 Indigenous South Australian adults. The prevalence of 'fair or poor' self-rated oral health was 33.5\%. The mean utility score was 0.82 (95\% Cl: 0.81-0.83). Compared with those rating their oral health as 'excellent or very good or good', those who rated their oral health as 'fair or poor' had a mean disutility score that was 1.6 ( $95 \% \mathrm{Cl}: 1.1-2.2)$ times higher, and the prevalence of at least one problem ranged from 90 to $160 \%$ higher for individual EQ-5D dimensions.

Conclusions: Fair or poor self-rated oral health among Indigenous persons in South Australia was associated with poor general health as measured by EQ-5D-5L disutility. The relationship was especially evident with respect to mobility, self-care and anxiety/depression. The findings emphasise the importance of oral health as predictors of general health among Indigenous Australians.

Keywords: Indigenous Australians, EuroQoL (EQ-5D-5L), Disutility score, Self-rated oral health

\footnotetext{
* Correspondence: xiangqun.ju@adelaide.edu.au

${ }^{1}$ Australian Research Centre for Population Oral Health, Adelaide Dental

School, The University of Adelaide, Adelaide 5005, Australia

Full list of author information is available at the end of the article
}

(c) The Author(s). 2021 Open Access This article is licensed under a Creative Commons Attribution 4.0 International License, which permits use, sharing, adaptation, distribution and reproduction in any medium or format, as long as you give appropriate credit to the original author(s) and the source, provide a link to the Creative Commons licence, and indicate if changes were made. The images or other third party material in this article are included in the article's Creative Commons licence, unless indicated otherwise in a credit line to the material. If material is not included in the article's Creative Commons licence and your intended use is not permitted by statutory regulation or exceeds the permitted use, you will need to obtain permission directly from the copyright holder. To view a copy of this licence, visit http://creativecommons.org/licenses/by/4.0/ The Creative Commons Public Domain Dedication waiver (http://creativecommons.org/publicdomain/zero/1.0/) applies to the data made available in this article, unless otherwise stated in a credit line to the data. 


\section{Background}

Aboriginal and Torres Strait Islander Australians (hereafter respectively termed 'Indigenous') comprise 3.3\% of the total Australian population [1]. They represent a rich and diverse culture, one which is steeped in an abundance of customs and languages. Prior to European settlement in the 1780s, the health and wellbeing of Indigenous Australians was characterised by physical strength and agility, diets free of refined carbohydrates, and environmental practises which had been sustained for approximately 65,000 years [2]. The rapid changes in lifestyle and diet, and sustained government policies of assimilation, discrimination and land dispossession, has had grave consequences on the health and wellbeing of contemporary Indigenous Australians [3].

Oral health is an integral part of general health. Dental caries and periodontal disease can cause debilitating pain, and result in tooth loss. This, in turn, may lead to difficulties with eating and speaking, embarrassment regarding aesthetics, inadequate masticatory capacity, and reduced nutrient intake due to changes in diet [4-6]. Dental diseases are associated with many chronic diseases, including type 2 diabetes [7], cardiovascular disease [8], kidney disease [9], and Alzheimer's disease [10]. Global self-ratings of oral health provide a useful insight into how patients view their oral health in a holistic sense, one which is unique and distinct from clinical diagnoses [11].

Health-related quality of life is the perceived quality of an individual's well-being or lack thereof. It includes emotional, social, and physical aspects of an individual's health. Instruments assessing healthrelated quality of life are commonly used as proxy measures of general health, and are represented by quality weights (utilities) [12]. Over 1000 instruments/ tools are available to assess quality of life [13], with the most commonly used being the.

'Short-Form 12-Item Health Survey version 2 (SF12v2)' instrument [14] to measure Health-Related Quality of Life (HRQOL), the World Health Organization Quality of Life Instruments (WHOQOLBREF) [15], and EuroQol (EQ-5D or EQ-5D-5L) [12, 16]. EQ-5D, a measure used to calculate quality adjusted life years (QALYs) to guide economic evaluations, is composed of five domains. Each dimension in the EQ-5D has been subdivided into five levels (5 L) to form EQ-5D-5L. EQ-5D is a widely utilised multi-attribute utility instrument used for estimating utility, and has been used to assess health-related quality of life among Indigenous populations, both in Australia [17, 18] and elsewhere [19, 20]. However, to the best of our knowledge EQ-5D-5L has not been used among the Indigenous Australian population to examine oral health outcomes.
Working in partnership with seven Indigenous communities in South Australia, this study aimed to: 1) quantify self-rated oral health and health-related quality of life and; 2) investigate associations between poor selfrated oral health and general health among Indigenous Australian adults.

\section{Methods}

Data was obtained from a large convenience sample $(n=1011)$ of Indigenous Australian adults in South Australia aged 18+ years between Feb 2018 and Jan 2019, as part of a broader study [21]. This study had the oversight of an Indigenous Reference Group (IRG), who advised on all aspects of project staff employment, participant recruitment, data collection, analysis and feedback. In the absence of a specific instrument to capture health-related quality of life through an Indigenous lens, the IRG endorsed items in the EQ-5D-5L as being an acceptable representation of their views of health and wellbeing. This was then pilot tested among eight Indigenous participants, who provided similar feedback. Validity and reliability of the EQ-5D-5L in the Indigenous Australian context has recently been assessed (in press). Participants were recruited through Aboriginal Community Controlled Health Organisations (ACCHOs), who were additional key stakeholders in the study.

\section{Data collection}

Data collection included face-to-face interviews by experienced research officers who were trained and calibrated in their delivery of the study aims, and managed by a senior Indigenous research officer. The self-report questionnaire included items pertaining to sociodemographic characteristics, self-rated oral health, oralhealth related behaviours and health-related quality of life.

\section{Variables}

The outcome variable was general health-related quality of life (general health), which was assessed using the EuroQoL instrument (EQ-5D-5L) [12]. The EQ-5D-5L is one of the most popular, validated tools for estimating general health-related quality of life. There are 5 dimensions (5D): mobility, self-care, usual activities, pain/discomfort and anxiety/ depression. Each dimension of the EQ-5D has five levels (5 L), with increasing level numbers corresponding to increasing levels of problems, described as: no problems; slight; moderate; severe; and extreme problems. A total possible 3125 health states were measured by combining one level from each dimension, ranging from the worst state (55555), five mild states $(21,111,12,111,11,211,11,121$, and 11,112$)$ to the full health state (11111), and evaluated by converting into a single index utility score using a scoring algorithm 
based on public preferences. To date, there are no values specific to the (five-level) EQ-5D-5L in Australia to summarise population data (and certainly none for the Indigenous Australian population), therefore the UK algorithm was used to calculate utility scores [12]. A small study in New Zealand $(n=66)$ tested validity of the EQ5D-3L among Maori [20]. The conclusions were that, while test-retest reliability was demonstrated, evidence of construct validity was not possible due to high numbers of missing values. An individual's overall utility score can be obtained by the full health score subtracting the score corresponding to each dimension's response level. For instance, the utility value '53124' as a health state means 'extreme problems with mobility, moderate problems with self-care, no problems with usual activities, slight problems with pain/discomfort and severe problems with anxiety/depression', should be 0.298 , i.e. 1.000 (full health) minus 0.274 (mobility level 5) minus 0.080 (self-care level 3) minus 0 (usual activities level 1) minus 0.063 (pain/ discomfort level 2) minus 0.285 (anxiety/ depression level 4) [12]. This study was focused on the poor general health status, so the disutility scores were used and calculated by 1 minus utility score correspondingly $[12,16]$. Higher disutility scores indicate worsening general health. In addition, pooled responses from the full health status (11111) to the worst state (55555) of the five dimensions of EQ-5D and were classified as 'no problems' or 'at least one problem' to explore association between individual EuroQoL dimensions and exposure variables.

The main exposure variable was self-rated oral health, which was assessed by the item 'Would you rate your oral health as...' with the five response levels dichotomised into 'fair/poor' and 'excellent/very good /good'. This is a global rating of oral health that has been used in population oral health surveys in Australia, the United Kingdom, New Zealand and many other Organisation for Economic Co-operation and Development (OECD) countries. Covariates included socio-demographic characteristics and health behaviours. The sociodemographic characteristics were 'Age'; dichotomised two groups ( $>50$ vs $\leq 50$ years); 'Sex' (Male vs Female); 'Geographic location' ('Metropolitan' vs 'Non-metropolitan'); 'Highest educational attainment' (dichotomised into 'High school or less' vs 'Trade/TAFE/University'; TAFE stands for 'Technical and Further Education' and provides training for vocational occupations); 'Income' (defined as 'Job' vs 'Welfare support payments'); ownership of a Government-administered health care card (HCC) (Yes vs No; a HCC is means-tested, and enables access to services such as publicly-funded dental care). The health-related behaviours included 'Tobacco smoking status' and 'Non-prescription tobacco substitute (vape, e-cigarette)'. These were defined as 'current smoker', 'ex-smoker' and 'never smoked'. 'Recreational drug use' was classified as 'Currently use', 'Don't now but used to' and 'Never used'.

\section{Data analysis}

Descriptive analyses were conducted to examine the distributions of socio-demographic, oral health and healthrelated behaviours, as well as (dis)utility scores. This was followed by bivariate analyses to describe associations with poor general health by estimating severity (mean disutility score) and prevalence (\% having at least one problem for individual dimensions) of EQ-5D-5L with their $95 \%$ confidence intervals $(95 \% \mathrm{CI})$. Differences were denoted to be statistically significant when $95 \% \mathrm{CI}$ did not overlap. Multivariable log-Poisson regression models were used to estimate associations between poor self-rated oral health and poor general health by calculating mean rate ratios (MRR) for disutility scores, and prevalence ratios (PR) for individual dimensions, after adjusting for social-demographic characteristics and health-related behaviours.

\section{Results}

Data were available for 1011 Indigenous South Australians aged $18+$ years who completed the self-rated oral health and EQ-5D-5L items. The mean age was 39.8 years (95\% CI: $38.9-40.7)$ and the mean utility score was 0.82 (95\% CI: 0.81-0.83).

The sample socio-demographic characteristics and mean disutility scores are summarised in Table 1. A higher proportion of the study sample were in the younger age group ( $\leq 50$ years), were female, owned a health care card, resided in non-metropolitan locations, received 'high school or less' education, relied on welfare for income, reported being current smokers of tobacco, never using non-prescription tobacco and recreational drugs, and rated their oral health as 'excellent/very good or good'.

The mean utility score of the sample (0.82) corresponds to a total mean disutility score of 0.18 (95\% CI: $0.17-0.19$ ). Higher disutility scores were observed among those rated their oral health as 'fair or poor' $(0.25,95 \%$ CI: $0.22-0.27)$, in the older age group $(0.26$, 95\% CI: $0.26-0.29$ ), who relied on welfare for income (0.19, 95\%CI: $0.18-0.21)$, owned a health care card $(0.19$, 95\%CI: $0.18-0.21)$, were current drug users $(0.21,95 \%$ CI: 0.18-0.23), comparing with their counterparts. (Table 1).

Overall, the prevalence of at least some problems for the five dimensions of EQ-5D ranged from less than $10 \%$ (self-care) to almost 60\% (anxiety/ depression) (Table 2). Indigenous Australians with fair/poor selfrated oral health had 1.5 to 2.5 times higher prevalence of problems (Level $>1$ for at least one domain) of the 
Table 1 Sample characteristics and disutility score (EQ-5D-5L) among Indigenous Australian adults

\begin{tabular}{|c|c|c|c|}
\hline & Number & Percentage & Disutility score \\
\hline & & $\%(95 \mathrm{Cl})$ & \\
\hline Total & 1011 & 100 & $0.18(0.17-0.19)$ \\
\hline Self-rated Oral health & & & \\
\hline Fair/Poor & 329 & $33.5(30.5-36.4)$ & $0.25(0.22-0.27)$ \\
\hline Excel/Nery good/Good & 654 & $66.5(63.6-69.5)$ & $0.15(0.13-0.16)$ \\
\hline Age groups (Years) & & & \\
\hline$>50$ & 283 & $28.0(25.2-30.8)$ & $0.26(0.22-0.29)$ \\
\hline$\leq 50$ & 728 & $72.0(69.2-74.8)$ & $0.15(0.14-0.17)$ \\
\hline Sex & & & \\
\hline Male & 340 & $33.6(30.7-36.5)$ & $0.17(0.15-0.19)$ \\
\hline Female & 671 & $66.4(63.5-69.3)$ & $0.19(0.17-0.20)$ \\
\hline Geographic location & & & \\
\hline Non-metropolitan & 633 & $62.7(59.7-65.7)$ & $0.17(0.15-0.19)$ \\
\hline Metropolitan & 376 & $37.3(34.3-40.3)$ & $0.20(0.18-0.22)$ \\
\hline Level of Education & & & \\
\hline High school or less & 679 & $68.2(65.3-71.1)$ & $0.17(0.16-0.19)$ \\
\hline Trade/TAFE/University & 317 & $31.8(28.9-34.7)$ & $0.20(0.18-0.22)$ \\
\hline Income & & & \\
\hline Welfare support payments & 757 & $76.0(73.3-78.7)$ & $0.19(0.18-0.21)$ \\
\hline Job & 239 & $24.0(21.3-26.7)$ & $0.14(0.12-0.17)$ \\
\hline Health Care Card ownership & & & \\
\hline Yes & 762 & $79.0(76.4-81.5)$ & $0.19(0.18-0.21)$ \\
\hline No & 203 & $21.0(18.5-23.6)$ & $0.15(0.12-0.17)$ \\
\hline Smoke status & & & \\
\hline Current smoker & 568 & $59.4(56.3-62.5)$ & $0.19(0.17-0.21)$ \\
\hline Ex-smoker & 113 & $11.8(9.8-113.9)$ & $0.21(0.17-0.26)$ \\
\hline Never smoked & 275 & $28.8(25.9-31.6)$ & $0.16(0.13-0.18)$ \\
\hline Use of non-prescription tob & e-cigarett & & \\
\hline Currently smoke & 116 & $12.1(10.0-14.2)$ & $0.19(0.15-0.22)$ \\
\hline Don't now but used to & 182 & $19.0(16.5-21.5)$ & $0.17(0.15-0.20)$ \\
\hline Never smoked & 660 & $68.9(66.0-71.8)$ & $0.18(0.16-0.19)$ \\
\hline Use of recreational drugs & & & \\
\hline Currently use & 208 & $20.9(18.3-23.4)$ & $0.21(0.18-0.23)$ \\
\hline Don't now but used to & 333 & $33.4(30.5-36.3)$ & $0.20(0.18-0.22)$ \\
\hline Never used & 456 & $45.7(42.6-48.8)$ & $0.16(0.14-0.18)$ \\
\hline
\end{tabular}

five EQ-5D dimensions than those rating their oral health as 'excellent, very good or good'. Consistent with the sample overall, the highest prevalence $(71.3 \%)$ of at least one problem was reported for the anxiety/ depression dimension.

Prevalence of at least one problem was higher in the older age group ( $>50$ years) than in the younger age group ( $\leq 50$ years) for all dimensions except anxiety/ depression, and the highest prevalence was $65 \%$ for pain/ discomfort. The prevalence of at least one problem was also higher among those dependent on welfare for income, and those with an HCC (with mobility around $31 \%$, self-care around $10 \%$ and usual activities around $27 \%$ in both cases), comparing with their counterparts. The prevalence of at least one problem was higher among current smokers and recreational drug users. A higher prevalence of at least one problem was also reported among metropolitan-dwelling participants (for 
Table 2 Bivariate association with prevalence of at least one problem for five dimensions of EQ-5D $(n=1011)$

\begin{tabular}{|c|c|c|c|c|c|}
\hline & $\begin{array}{l}\text { Mobility: at least } \\
\text { one problem } \\
\%(95 \% \mathrm{Cl})\end{array}$ & $\begin{array}{l}\text { Self-care: at least } \\
\text { one problem } \\
\%(95 \% \mathrm{Cl})\end{array}$ & $\begin{array}{l}\text { Usual activities: at } \\
\text { least one problem } \\
\%(95 \% \mathrm{Cl})\end{array}$ & $\begin{array}{l}\text { Pain/discomfort: at } \\
\text { least one problem } \\
\%(95 \% \mathrm{Cl})\end{array}$ & $\begin{array}{l}\text { Anxiety/depression: } \\
\text { at least one problem } \\
\%(95 \% \mathrm{Cl})\end{array}$ \\
\hline Total & $28.6(25.8-31.4)$ & $9.0(7.2-10.8)$ & $24.8(22.1-27.5)$ & $52.2(49.1-55.3)$ & $58.3(55.2-61.3)$ \\
\hline \multicolumn{6}{|l|}{ Self-rated oral health } \\
\hline Fair/Poor & $42.9(37.6-48.3)$ & $14.7(10.8-18.5)$ & $35.0(29.8-40.1)$ & $66.8(61.6-71.9)$ & $71.3(66.4-76.2)$ \\
\hline Excel/Nery good/Good & $21.2(18.1-24.3)$ & $6.0(4.2-7.8)$ & $19.4(16.3-22.4)$ & $45.1(41.2-48.9)$ & $51.8(48.0-55.7)$ \\
\hline \multicolumn{6}{|l|}{ Age groups (Years) } \\
\hline$>50$ & $50.5(44.7-56.4)$ & $16.8(12.4-21.2)$ & $40.8(35.0-46.5)$ & $65.1(59.5-70.7)$ & $58.4(52.6-64.2)$ \\
\hline$\leq 50$ & $20.0(17.1-22.9)$ & $6.0(4.2-7.7)$ & $18.6(15.7-21.4)$ & $47.1(43.5-50.8)$ & $58.2(54.6-61.8)$ \\
\hline \multicolumn{6}{|l|}{ Sex } \\
\hline Male & $27.3(22.5-32.1)$ & $9.2(6.1-12.3)$ & $24.9(20.2-29.5)$ & $51.3(46.0-56.7)$ & 55.7 (50.3-61.0) \\
\hline Female & $29.2(25.8-32.7)$ & $8.9(6.7-11.1)$ & $24.8(21.5-28.1)$ & $51.6(48.8-56.4)$ & $59.6(55.8-63.3)$ \\
\hline \multicolumn{6}{|l|}{ Geographic location } \\
\hline Non-metropolitan & $28.3(24.8-31.9)$ & $8.7(6.4-10.9)$ & $23.8(20.5-27.1)$ & $48.5(44.5-52.4)$ & $52.8(48.9-56.7)$ \\
\hline Metropolitan & $29.1(24.5-33.8)$ & $9.6(6.6-12.6)$ & $26.7(22.2-31.2)$ & $58.3(53.3-63.4)$ & $67.5(62.7-72.2)$ \\
\hline \multicolumn{6}{|l|}{ Level of Education } \\
\hline High school or less & $27.4(24.1-30.8)$ & $9.2(7.0-11.4)$ & $23.0(19.9-26.2)$ & $48.3(44.5-52.1)$ & $55.9(52.2-59.7)$ \\
\hline Trade/TAFE/University & $31.0(25.9-36.1)$ & $8.6(5.5-11.7)$ & $28.9(23.9-33.9)$ & $61.0(55.6-66.3)$ & $64.1(58.8-69.4)$ \\
\hline \multicolumn{6}{|l|}{ Income } \\
\hline Welfare support payments & $31.0(27.7-34.3)$ & $10.2(8.1-12.4)$ & $27.6(24.4-30.8)$ & $52.2(48.6-55.8)$ & $59.2(56.0-63.4)$ \\
\hline Job & $19.7(14.6-24.7)$ & $5.0(2.2-7.8)$ & $16.3(11.6-21.0)$ & $51.9(45.5-58.2)$ & $56.5(50.2-62.8)$ \\
\hline \multicolumn{6}{|l|}{ Health Care Card ownership } \\
\hline Yes & $31.2(27.9-34.5)$ & $10.7(8.5-12.9)$ & $27.0(23.8-30.2)$ & $50.8(47.2-54.4)$ & $57.8(54.3-61.3)$ \\
\hline No & $18.2(12.9-23.5)$ & $3.0(0.6-5.3)$ & $18.2(12.9-23.5)$ & $58.4(51.6-65.2)$ & $61.4(54.7-68.1)$ \\
\hline \multicolumn{6}{|l|}{ Smoke status } \\
\hline Current smoker & $28.3(24.6-32.0)$ & $9.6(7.2-12.0)$ & $25.7(22.1-29.3)$ & $52.7(48.5-56.8)$ & $61.6(57.5-65.6)$ \\
\hline Ex-smoker & $37.2(28.2-46.1)$ & $8.8(3.6-14.1)$ & $27.4(19.2-35.7)$ & $61.1(52.1-70.1)$ & $61.9(53.0-70.9)$ \\
\hline Never smoked & $25.5(20.3-30.6)$ & $8.0(4.8-11.3)$ & $22.2(17.3-27.1)$ & $48.9(43.0-54.8)$ & $50.9(45.0-56.9)$ \\
\hline \multicolumn{6}{|c|}{ Use of non-prescription tobacco substitutes (vape, e-cigarette) } \\
\hline Currently smoke & $26.5(18.4-34.7)$ & $10.6(4.9-16.3)$ & $28.1(19.8-36.3)$ & $49.6(40.4-58.7)$ & $64.2(55.6-73.1)$ \\
\hline Don't now but used to & $26.9(20.5-33.4)$ & $9.1(5.1-13.6)$ & $26.9(20.5-33.4)$ & $52.5(45.2-59.8)$ & $61.9(54.8-69.0)$ \\
\hline Never smoked & $29.2(25.7-32.7)$ & $7.9(5.8-10.0)$ & $23.7(20.4-26.9)$ & $52.0(48.2-55.8)$ & $56.2(52.4-60.0)$ \\
\hline \multicolumn{6}{|l|}{ Use of recreational drugs } \\
\hline Currently use & $27.8(21.7-33.9)$ & $9.2(5.3-13.2)$ & $28.0(21.9-34.1)$ & $56.0(49.3-62.8)$ & $70.4(64.1-76.6)$ \\
\hline Don't now but used to & $28.6(23.7-33.5)$ & $10.8(7.5-14.2)$ & $27.7(22.9-32.5)$ & $56.0(50.6-61.4)$ & $66.1(60.9-71.2)$ \\
\hline Never used & $29.1(24.9-33.3)$ & $7.5(5.1-9.9)$ & $21.4(17.6-25.1)$ & $48.0(43.4-52.6)$ & $47.7(43.1-52.3)$ \\
\hline
\end{tabular}

pain/discomfort (58\%) and anxiety/depression (68\%)), and 'Trade/TAFE/University' education (for pain/discomfort; 61\%)).

Fair/poor self-rated oral health was positively associated with overall total disutility score, as well as each dimension of EQ-5D (Table 3). After adjusting for all covariates, the mean disutility score was 1.6 times higher, and the prevalence of at least one problem ranged from 87 to $162 \%$ higher risk across each individual EQ-5D dimension among those reporting fair/poor self-rated oral health. Older age and current drug use were also significantly associated with total disutility and most individual EQ-5D dimensions. Factors significantly associated with one or more problems in the EQ-5D dimensions included: self-care with health care card ownership and usual activities with income; pain/discomfort 
Table 3 Multivariable regression modelling for total disutility scores (Mean rate ratio: MRR) and at least one problem for 5 dimensions (prevalence ratio: PR) of EQ-5D $(n=1011)$

\begin{tabular}{|c|c|c|c|c|c|c|}
\hline & $\begin{array}{l}\text { Disutility scores } \\
\text { MRR }(95 \% \mathrm{Cl})\end{array}$ & $\begin{array}{l}\text { Mobility } \\
\text { PR }(95 \% \mathrm{Cl})\end{array}$ & $\begin{array}{l}\text { Self-care } \\
\text { PR }(95 \% \mathrm{Cl})\end{array}$ & $\begin{array}{l}\text { Usual activities } \\
\text { PR }(95 \% \mathrm{Cl})\end{array}$ & $\begin{array}{l}\text { Pain/Discomfort } \\
\text { PR }(95 \% \mathrm{Cl})\end{array}$ & $\begin{array}{l}\text { Anxiety/Depression } \\
\text { PR }(95 \% \mathrm{Cl})\end{array}$ \\
\hline \multicolumn{7}{|l|}{ Self-rated oral health } \\
\hline Fair/Poor & $1.56(1.12-2.17)$ & $2.53(1.81-3.56)$ & $2.62(1.55-4.41)$ & $1.87(1.32-2.64)$ & $2.24(1.63-3.07)$ & $2.41(1.73-3.36)$ \\
\hline Excel/Nery good/Good & ref & ref & ref & ref & ref & ref \\
\hline \multicolumn{7}{|l|}{ Age groups (Years) } \\
\hline$>50$ & $1.60(1.12-2.31)$ & $3.88(2.26-5.62)$ & $2.75(1.57-4.80)$ & $2.79(1.91-4.07)$ & $2.05(1.44-2.93)$ & $1.15(0.81-1.65)$ \\
\hline$\leq 50$ & ref & ref & ref & ref & ref & ref \\
\hline \multicolumn{7}{|l|}{ Sex } \\
\hline Male & $0.86(0.60-1.25)$ & $0.93(0.64-1.36)$ & $1.07(0.61-1.89)$ & $0.94(0.64-1.36)$ & $0.86(0.62-1.19)$ & $0.63(0.45-0.87)$ \\
\hline Female & ref & ref & ref & ref & ref & ref \\
\hline \multicolumn{7}{|l|}{ Geographic location } \\
\hline Non-metropolitan & $0.85(0.61-1.19)$ & $0.93(0.66-1.31)$ & $0.87(0.51-1.48)$ & $0.88(0.62-1.23)$ & $0.68(0.51-0.93)$ & $0.57(0.42-0.79)$ \\
\hline Metropolitan & ref & ref & ref & ref & ref & ref \\
\hline \multicolumn{7}{|l|}{ Level of Education } \\
\hline High school or less & $0.93(0.65-1.34)$ & $0.73(0.51-1.06)$ & $1.01(0.57-1.80)$ & $0.71(0.49-1.03)$ & $0.72(0.52-1.00)$ & $0.93(0.66-1.31)$ \\
\hline Trade/TAFE/University & ref & ref & ref & ref & ref & ref \\
\hline \multicolumn{7}{|l|}{ Income } \\
\hline Welfare support payments & $1.15(0.68-1.96)$ & $1.33(0.78-2.27)$ & $1.14(0.47-2.77)$ & $1.83(1.05-3.17)$ & $1.18(0.76-1.83)$ & $0.98(0.62-1.54)$ \\
\hline Job & ref & ref & ref & ref & ref & ref \\
\hline \multicolumn{7}{|l|}{ Health Care Card ownership } \\
\hline Yes & $1.11(0.65-1.90)$ & $1.62(0.93-2.81)$ & $5.67(1.53-21.0)$ & $1.06(0.61-1.82)$ & $0.68(0.44-1.07)$ & $0.86(0.55-1.36)$ \\
\hline No & ref & ref & ref & ref & ref & ref \\
\hline \multicolumn{7}{|l|}{ Smoke status } \\
\hline Current smoker & $1.04(0.69-1.58)$ & $1.21(0.80-1.85)$ & $0.97(0.51-1.83)$ & $1.05(0.69-1.61)$ & $1.00(0.70-1.43)$ & $1.07(0.74-1.54)$ \\
\hline Ex-smoker & $1.07(0.61-1.87)$ & $1.42(0.80-2.50)$ & $0.59(0.21-1.61)$ & $0.76(0.42-1.39)$ & $1.16(0.69-1.94)$ & $0.99(0.58-1.67)$ \\
\hline Never smoked & ref & ref & ref & ref & ref & ref \\
\hline \multicolumn{7}{|c|}{ Use of non-prescription tobacco substitutes (vape, e-cigarette) } \\
\hline Currently smoke & $0.94(0.56-1.60)$ & $0.83(0.48-1.44)$ & $1.19(0.54-2.65)$ & $1.02(0.59-1.76)$ & $0.77(0.48-1.24)$ & $0.97(0.59-1.60)$ \\
\hline Don't now but used to & $0.87(0.56-1.36)$ & $0.85(0.54-1.33)$ & $0.89(0.44-1.80)$ & $1.21(0.77-1.88)$ & $0.93(0.63-1.37)$ & $1.04(0.69-1.55)$ \\
\hline Never smoked & ref & ref & ref & ref & ref & ref \\
\hline \multicolumn{7}{|l|}{ Use of recreational drugs } \\
\hline Currently use & $1.33(0.83-2.13)$ & $0.87(0.53-1.43)$ & $0.95(0.42-2.13)$ & $1.52(0.93-2.49)$ & $1.73(1.14-2.64)$ & $2.75(1.78-4.28)$ \\
\hline Don't now but used to & $1.61(1.06-2.43)$ & $1.57(1.04-2.38)$ & $2.51(1.31-4.81)$ & $2.34(1.52-3.60)$ & $2.11(1.46-3.06)$ & $2.67(1.84-3.89)$ \\
\hline Never used & ref & ref & ref & ref & ref & ref \\
\hline
\end{tabular}

with metropolitan residential location; and anxiety/depression with male, sex and metropolitan residential location.

\section{Discussion}

This study is the first to evaluate general health-related quality of life - using EQ-5D $5 \mathrm{~L}$, and to estimate associations with self-rated oral health, among Indigenous Australians. Our findings demonstrated that poorer self- rated oral health was associated with higher disutility scores, as well as higher prevalence of at least one problem in each of the five EQ-5D dimensions (indicating poorer general health). Being older, male, residing in metropolitan locations, relying on the government for income, ownership of a health care card, never consuming alcohol and current recreational drug use were also significantly associated with high disutility scores and/or individual EQ-5D dimensions, after adjustment in multivariable models. 
It is important to acknowledge that, overall, the degree of utility was low (0.82) in the study compared with estimates from the non-Indigenous Australian population (0.91) [16]. This suggests the general health-related quality of life among Indigenous Australians in our study is, on the whole, poorer than the general Australian population. This finding is in keeping with many studies and national health reports [22, 23] suggesting that Indigenous Australians score worse on almost every indicator of health well-being relative to non-Indigenous populations. Our findings provide evidence of poorer general health (based on EQ-5D5L) for the Indigenous Australian population compared with the Australian population overall.

Our findings also indicate that poor self-rated oral health is associated with poor general health-related quality of life among Indigenous Australians. The findings are consistent with previous studies for the general population $[6,24,25]$. In a representative population in South Australia, people with less than 21 teeth had 2 times higher disutility, and had 26 and 16\% higher risk of reporting at least one problem in mobility and pain/ discomfort respectively, after adjusting for other covariates [24]. Other evidence suggests that health-related quality of life improves for patients who receive root canal treatment, compared with those had tooth extraction [6]. Xerostomia (dry mouth, usually caused by medication) is usually associated with poor oral and general health [25]. This has been attributed to many factors, including the social determinants of health, longterm impacts of colonisation, dental/health service provision models that do not favour Indigenous holistic models of care, and inequitable access to dental/health services in part the consequence of regional and remote geographic location of residence (refs), results in increasing psychological distress, trauma, socioeconomic disadvantage, and high burden of chronic diseases.

Although EQ-5D has been used to assess health-related quality of life among Indigenous Australians, the need for health-related quality of life instruments that are specifically tailored for Indigenous populations is recognised [26, 27]. Indigenous conceptions of health differ from the conceptions of non-Indigenous persons in fundamental ways that are not captured by generic quality of life instruments. Constructs that lie outside the five EuroQoL domains are not taken into account, such as social, cultural, diet, land use, community and experiences of dispossession, colonisation, racism and assimilation domains, We acknowledge that the EuroQoL instrument captures only a small component of what constitutes health in the Indigenous lens, but chose to use it in the absence of another instrument that had been tested and validated in Australia at the time of the study, and after endorsement by the study's IRG. It is interesting to note that Perkins and colleagues [20] reported that over three quarters of their
Maori sample in New Zealand agreed that the EQ-5D adequately represented their concept of health. Angell and colleagues [26] also noted that some existing HRQoL measures were used in Indigenous populations, with four instruments deemed to be valid (excluding EQ-5D or EQ5D-5L). Moving forward, it is essential that the value of health-related quality of life Indigenous populations is encapsulated in a manner that better reflects all of those aspects of health which are important for Indigenous people.

Strengths of this study include: 1 ) it is the first to work in partnership with the Indigenous Australian community to report self-rated oral health and health-related quality of life; 2) a large representation of the broader South Australian Indigenous population $(n=1011$, Table 1 ) is critical, with the findings potentially having meaning for other Indigenous groups residing in similar socio-economic regions of the world. Limitations of this study include the lack of oral clinical examination data, with no ability to correlate actual clinical dental disease status against impacts on daily life. In addition, our findings could be affected due to the proportion of older age (> 50 years), female, non-metropolitan location, welfarebased income, health care card holder and currently smoking being higher in this South Australian Indigenous population than in broader Indigenous population (see Supplements Table S1).

In conclusion, our findings indicate that general health-related quality of life was lower among the sampled Indigenous population than previously reported for non-Indigenous populations, and also that poor selfrated oral health was associated with poor general health in this Indigenous population, including across all five dimensions assessed in EQ-5D. Most oral health conditions are preventable and can be treated in their early stages. Our findings therefore suggest that improving oral health would also improve broader aspects of health-related quality of life. Our findings are an important contribution to cost-utility (such as measurements of utilities for more specific oral health states: dental caries, periodontal disease and oral cancers) and disease prevention strategies that seek to inform policies around improving oral health among all Australians.

\section{Supplementary Information}

The online version contains supplementary material available at https://doi. org/10.1186/s12889-021-10426-3.

Additional file 1: Table S1. Socio-demographic characteristics, healthrelated behaviours including tobacco, alcohol and drug use (percent, 95\% Cl) and compared against population estimates in 2016.

\section{Abbreviations}

ACCHOs: Aboriginal Community Controlled Health Organisations;

$\mathrm{Cl}$ : Confidence intervals; EuroQoL: Europe Quality of life; EQ-5D-5L: EuroQoL- 
five dimensions-five levels; HCC: Health care card; HRQOL: Health-Related Quality of Life; IRG: Indigenous Reference Group; MRR: Mean rate ratio; OHRQoL: Oral health-related quality of life; PR: Prevalence ratio; QALYs: Quality adjusted Life Years; TAFE: Technical and Further Education; WHOQO-BREF: World Health Organization Quality of Life

\section{Acknowledgements}

This study was governed by an Indigenous Reference Group, who oversaw the orchestration, delivery and feedback of the study findings as it relates to the health and well-being of Indigenous Australians. We sincerely acknowledge and appreciate all that this Reference Group did. We also thank and acknowledge all study participants, and the staff who collected data.

\section{Authors' contributions}

LMJ and KC conceived and designed the study. XJ did the statistical analyses, produced the figures, interpreted the data and contributed to writing manuscript drafts. LMJ, KC, MS and GG are guarantors for this article. All authors contributed to data acquisition and interpretation, and critically reviewed and approved the manuscript.

\section{Funding}

Funding is from a National Health and Medical Research Council (NHMRC) project grant (APP1120215). LMJ is supported by a NHMRC Senior Research Fellowship (APP1102587). MAS receives salary support from the NHMRC (APP1159491) and Cancer Institute NSW (ECF181561). GG is supported by a NHMRC Investigator Grant (APP1176651).

\section{Availability of data and materials}

The datasets generated and/or analyzed during the current study are not publicly available due to privacy issues of the participants. Data are available from the corresponding author on reasonable request.

\section{Ethics approval and consent to participate}

Ethics approval has been obtained from the University of Adelaide Human Research Ethics Committee (H-2016-246) and the Aboriginal Health Council of South Australia (04-17-729). All participants were provided with an information sheet outlining the study objectives and signed an informed consent form.

\section{Consent for publication}

Not applicable.

\section{Competing interests}

The authors confirm that they have no competing interests.

\section{Author details}

'Australian Research Centre for Population Oral Health, Adelaide Dental School, The University of Adelaide, Adelaide 5005, Australia. ${ }^{2}$ Menzies School of Health Research, Darwin, Australia. ${ }^{3}$ Cancer Council of NSW, Woolloomooloo, Australia. ${ }^{4}$ School of Public Health, University of Sydney, Sydney, Australia.

Received: 1 October 2020 Accepted: 10 February 2021

Published online: 01 March 2021

\section{References}

1. Statistics Abo. National Aboriginal and Torres Strait Islander Social Survey. https://www.abs.gov.au/ausstats/abs@.nsf/mf/3238.0.55.001.2019.

2. Davidson I. The colonization of Australia and its Adjacent Islands and the evolution of modern cognition. Curr Anthropol. 2010;51:S177-S89.

3. Gracey M. Closing the Aboriginal health gap. Lancet. 2019;394(10194):218.

4. Adegboye AR, Twetman S, Christensen LB, Heitmann BL. Intake of dairy calcium and tooth loss among adult Danish men and women. Nutrition. 2012;28(7-8):779-84

5. Liang YH, Chou C, Chen YJ, Chou YF, Lin CY, Chou C, et al. Impact of periodontal disease and chewing ability on the quality of life of the elderly in an affluent community. J Formos Med Assoc. 2020;119(11):1693-1701.

6. Wigsten $E$, Kvist $T$, Jonasson $P$, Davidson $T$. Comparing quality of life of patients undergoing root canal treatment or tooth extraction. J Endod. 2020;46(1):19-28 e1.
7. Takahara M, Katakami N, Shiraiwa T, Abe K, Ayame H, Ishimaru Y, et al. Evaluation of health utility values for diabetic complications, treatment regimens, glycemic control and other subjective symptoms in diabetic patients using the EQ-5D-5L. Acta Diabetol. 2019;56(3):309-19.

8. Peng J, Song J, Han J, Chen Z, Yin X, Zhu J, et al. The relationship between tooth loss and mortality from all causes, cardiovascular diseases, and coronary heart disease in the general population: systematic review and dose-response metaanalysis of prospective cohort studies. Biosci Rep. 2019;39(1):BSR20181773.

9. Ruokonen H, Nylund K, Meurman JH, Heikkinen AM, Furuholm J, Sorsa T, et al. Oral symptoms and oral health-related quality of life in patients with chronic kidney disease from predialysis to posttransplantation. Clin Oral Investig. 2019;23(5):2207-13.

10. Dioguardi M, Gioia GD, Caloro GA, Capocasale G, Zhurakivska K, Troiano G, et al. The Association between Tooth Loss and Alzheimer's Disease: a Systematic Review with Meta-Analysis of Case Control Studies. Dent J (Basel). 2019;7(2):49.

11. Lawal FB. Global self-rating of oral health as summary tool for oral health evaluation in low-resource settings. J Int Soc Prev Community Dent. 2015; 5(Suppl 1):S1-6.

12. Devlin NJ, Shah KK, Feng Y, Mulhern B, van Hout B. Valuing healthrelated quality of life: an EQ-5D-5L value set for England. Health Econ. 2018;27(1):7-22.

13. Ubel PA, Loewenstein G, Jepson C. Whose quality of life? A commentary exploring discrepancies between health state evaluations of patients and the general public. Qual Life Res. 2003;12(6):599-607.

14. Jalali-Farahani S, Amiri P, Karimi M, Vahedi-Notash G, Amirshekari G, Azizi F. Perceived social support and health-related quality of life (HRQoL) in Tehranian adults: Tehran lipid and glucose study. Health Qual Life Outcomes. 2018;16(1):90.

15. Skevington SM, Lotfy M, O'Connell KA. The World Health Organization's WHOQOL-BREF quality of life assessment: psychometric properties and results of the international field trial. A report from the WHOQOL group. Qual Life Res. 2004;13(2):299-310.

16. McCaffrey N, Kaambwa B, Currow DC, Ratcliffe J. Health-related quality of life measured using the EQ-5D-5L: south Australian population norms. Health Qual Life Outcomes. 2016;14(1):133.

17. Nagel T, Sweet M, Dingwall KM, Puszka S, Hughes JT, Kavanagh DJ, et al. Adapting wellbeing research tools for Aboriginal and Torres Strait islander people with chronic kidney disease. BMC Nephrol. 2020;21(1):130.

18. Dingwall KM, Nagel T, Hughes JT, Kavanagh DJ, Cass A, Howard K, et al. Wellbeing intervention for chronic kidney disease (WICKD): a randomised controlled trial study protocol. BMC Psychol. 2019;7(1):2.

19. Guevara SV, Feican EA, Pelaez I, Valdiviezo WA, Montaleza MA, Molina GM, et al. Prevalence of rheumatic diseases and quality of life in the Saraguro indigenous people, Ecuador: A Cross-sectional Community-Based Study. J Clin Rheumatol. 2019.

20. Perkins MR, Devlin NJ, Hansen P. The validity and reliability of EQ-5D health state valuations in a survey of Maori. Qual Life Res. 2004;13(1):271-4.

21. Jamieson L, Garvey G, Hedges J, Mitchell A, Dunbar T, Leane C, et al. Human papillomavirus and Oropharyngeal Cancer among indigenous Australians: protocol for a prevalence study of Oral-related human papillomavirus and cost-effectiveness of prevention. JMIR Res Protoc. 2018;7(6):e10503.

22. Chand R, Parker E, Jamieson L. Differences in, and frames of reference of, indigenous Australians' self-rated general and Oral health. J Health Care Poor Underserved. 2017;28(3):1087-103.

23. ABS. National Aboriginal and Torres Strait Islander Social Survey. http:// www.abs.gov.au/ausstats/abs@.nsf/mf/4714.0.55.003.2008.

24. Jamieson L, Brennan D, Peres MA, Luzzi L, Miller C, Bowden J, et al. Having fewer than 21 teeth associated with poorer general health among south Australians. J Public Health Dent. 2017;77(3):216-24.

25. Flink $H$, Tegelberg A, Arnetz JE, Birkhed D. Self-reported oral and general health related to xerostomia, hyposalivation, and quality of life among caries active younger adults. Acta Odontol Scand. 2020;78(3):229-35.

26. Angell B, Muhunthan J, Eades AM, Cunningham J, Garvey G, Cass A, et al. The health-related quality of life of indigenous populations: a global systematic review. Qual Life Res. 2016;25(9):2161-78.

27. Butler TL, Anderson K, Garvey G, Cunningham J, Ratcliffe J, Tong A, et al. Aboriginal and Torres Strait islander people's domains of wellbeing: a comprehensive literature review. Soc Sci Med. 2019;233:138-57.

\section{Publisher's Note}

Springer Nature remains neutral with regard to jurisdictional claims in published maps and institutional affiliations. 